\title{
HUBUNGAN PENGETAHUAN DAN SIKAP MURID SD TERHADAP PERSONAL HYGIENE
}

\author{
${ }^{1}$ Vetri Nathalia, ${ }^{2}$ Gito Vakol \\ 1,2akademi Keperawatan Nabila \\ Email :vetri.nathalia@yahoo.com
}

\begin{abstract}
Personal hygiene is a way of maintaining one's personal health both physically and psychologically which aims to prevent the outbreak of illness and improve health status. Data from the Padang Panjang City Health Office, the highest percentage of personal hygiene problems occurred at Merapi Padang Panjang Elementary School at 68\%. The purpose of this study was to determine the relationship between students' knowledge and attitudes to personal hygiene. This study uses descriptive correlational method using cross-sectional design. The sample technique used in this study is total sampling. The study was conducted in May 2018 with a sample of 80 students at SD Merapi Padang Panjang. Data collection techniques using questionnaires. The statistical test used is chisquere. The results of this study revealed $53.8 \%$ of students' knowledge about personal hygiene was low, $51.2 \%$ of students' attitudes about personal hygiene were classified as negative, 55\% of students' personal hygiene was bad. There is a significant relationship between knowledge and attitudes to personal hygiene students of Padang Panjang Merapi Elementary School in 2018 with a value of $p=0,000$. It is expected that teachers pay more attention to knowledge and attitudes to personal hygiene of elementary students because knowledge and attitudes can have the most influence on health status.
\end{abstract}

Keywords : Knowledge, Attitudes, Personal Hygiene Age

\begin{abstract}
ABSTRAK
Personal hygiene merupakan suatu cara pemeliharaan kesehatan diri seseorang baik fisik maupun psikis yang bertujuan untuk mencegah terjangkitnya penyakit serta memperbaiki status kesehatan. Data dari Dinas Kesehatan Kota Padang Panjang persentase masalah personal hygiene tertinggi terjadi di SD Merapi Padang Panjang sebesar 68\%. Tujuan dari penelitian ini adalah mengetahui hubungan pengetahuan dan sikap murid terhadap personal hygiene. Penelitian ini mengunakan metode deskriptif korelasional dengan mengunakan desain cross-sectional. Teknik sampel yang digunakan dalam penelitian ini adalah dengan menggunakan total sampling. Pada penelitian dilakukan pada bulan Mei 2018 dengan jumlah sampel 80 murid di SD Merapi Padang Panjang. Teknik pengumpulan data menggunakan kuesioner. Uji statistik yang dipakai adalah chi-squere. Hasil penelitian ini mengungkap 53,8\% pengetahuan murid tentang personal hygiene tergolong rendah, 51,2\% sikap murid tentang personal hygiene tergolong negatif, 55\% personal hygiene murid tergolong buruk. Terdapat hubungan yang signifikan antara pengetahuan dan sikap terhadap personal hygiene murid SD Merapi Padang Panjang Tahun 2018 dengan nilai $\mathrm{p}=0,000$. Diharapkan kepada guru lebih memperhatikan pengetahuan dan sikap terhadap personal hygiene murid SD karena pengetahuan dan sikap dapat memberikan pengaruh paling besar terhadap status kesehatan.
\end{abstract}

Kata Kunci : Pengetahuan, Sikap, Personal Hygiene 


\section{PENDAHULUAN}

Personal hygiene adalah suatu cara pemeliharaan kesehatan diri seseorang baik fisik maupun psikis yang bertujuan untuk mencegah terjangkitnya penyakit serta memperbaiki status kesehatan. Salah satu bentuk pemeliharaan kesehatan diri adalah perawatan rongga gigi dan mulut (Isro'in, 2012).

Selain itu kaki, tangan dan kuku membutuhkan perhatian khusus dalam perawatan kebersihan diri seseorang karena rentan terhadap infeksi. Setiap kondisi yang mengenai tangan dan kaki secara otomatis akan mempengaruhi kemampuan dalam hal perawatan kebersihan diri seseorang. Kuku merupakan salah satu anggota badan yang terdapat pada ujung jarijari tangan dan kaki yang mengandung lapisan tanduk (Isro'in \& Andarmoyo, 2012).

Kebersihan kaki, tangan, dan kuku menjadi hal yang penting untuk diperhatikan kebersihannya terutama ketika sedang sakit, perawatannya menjadi semakin penting untuk diperhatikan. Kuku yang tidak terawat juga dapat mengakibatkan masalah kesehatan. Beberapa masalah akibat tidak terawatnya kuku misalnya kuku yang panjang dapat mengakibatkan kuku menjadi mudah robek dan dapat melukai kulit sekitar, kuku yang tumbuh kedalam menuju jaringan lunak sekitar kuku karena pemotongan kuku yang salah (Isro'in \& Andarmoyo, 2012).

Perilaku menjaga kebersihan diri dipengaruhi oleh berbagai faktor, seperti faktor pengetahuan, sosial, budaya, kebiasaan, citra tubuh, sosial ekonomi, dan kondisi fisik (Tarwoto \& Wartonah, 2006). Faktor-faktor tersebut ada yang bisa diubah dan tidak dapat diubah. Faktor-faktor yang dapat diubah adalah faktor pengetahuan, sosial, kebiasaan, sosial ekonomi, dan kondisi fisik salah satu cara merubah faktor tersebut adalah dengan memperbaiki tingkat pengetahuan melalui pendidikan kesehatan (Notoatmodjo, 2011).

Pendidikan kesehatan merupakan program kesehatan yang dirancang untuk mempengaruhi individu dan masyarakat agar berpikir, bersikap, dan berperilaku positif dengan tujuan meningkatkan kesehatan pendidikan kesehatan berpengaruh pada peningkatan pengetahuan dan perilaku personal hygiene pada anak usia sekolah (Notoatmodjo, 2011).

Pengetahuan masyarakat yang kurang mengakibatkan pola perilaku hidup bersih dan sehat menjadi sulit untuk diterapkan dalam kehidupan sehari-hari. Masalah personal hygiene dianggap kurang penting karena kurangnya pengetahuan mereka terhadap pentingnya PHBS ( prilaku hidup bersih dan sehat), penelitian dari (Kusumawati, 2008).

Anak usia Sekolah Dasar (SD) merupakan masa tumbuh kembang yang baik. Masa ini anak perlu mendapatkan pengawasan terhadap kesehatannya karena usia sekolah adalah masa dimana anak-anak mempunyai banyak aktivitas, dan aktivitas tersebut seringkali berhubungan langsung dengan lingkungan yang kotor dan menyebabkan anak mudah terserang penyakit. Perawatan kuku pada anak juga sering kali terabaikan oleh orang tua. Kurangnya pengetahuan dan kesadaran orang tua dalam memperhatikan personal hygiene anak menyebabkan anak juga tidak 
memperhatikan kebersihan dirinya sendiri. Meskipun terlihat sepele, tetapi perawatan kuku juga merupakan hal penting yang harus diperhatikan dan kesehatan mulut (Wong, 2009).

Usaha Kesehatan Sekolah (UKS), perlu didirikan dalam rangka untuk meningkatkan perilaku personal hygiene pada anak usia sekolah dasar, usaha kesehatan sekolah mempunyai peranan penting terhadap pemantauan kesehatan anak-anak di sekolah. Selain itu. Usaha Kesehatan Sekolah juga berfungsi memberikan pengetahuan tentang kesehatan, seperti cara menjaga kebersihan diri, mengobati luka dengan benar, perawatan kuku, serta penerapan perilaku kesehatan yang lainnya (Wong, 2009).

Dampak dari kurangnya menjaga kebersihan mulut salah satunya adalah kanker mulut, di negara maju seperti Amerika Serikat (25\%) dari 30.000 warganya meninggal akibat kanker mulut, oleh karena itu perlu menjaga kesehatan mulut kita supaya tetap bersih dan terhindar dari penyakit (Rahmadhan, 2010).

Angka penyakit gigi dan mulut terutama karies di Indonesia masih banyak di derita, baik oleh anak-anak maupun dewasa. Data Kementerian Kesehatan 2010 menunjukkan, bahwa prevalensi karies di Indonesia mencapai $(60-80 \%)$ dari populasi, serta menempati peringkat ke 6 sebagai penyakit yang paling banyak yang di derita (Kemenkes, 2011).

Hasil Riskesdas (2007), melaporkan bahwa prevalensi karies gigi di Indonesia adalah sebesar 46,5 dengan penjabaran prevalensi karies untuk kelompok usia 12 tahun sebesar (36,1\%) dengan Desay, Missing, Filling Tooth (DMF-T) 0,91, kelompok usia 35-44 tahun prevalensi karies gigi mencapai 80,5 dengan DMF-T 4,46 sedangkan usia diatas 65 tahun dengan prevalensi karies sebesar $(94,4 \%)$ dan DMF-T 18,33.

Batasan kesehatan menurut Undang-Undang Kesehatan No.23 Tahun 1992 menjelaskan keadaan sejahtera badan, jiwa, dan sosial yang memungkinkan setiap orang hidup secara sosial dan ekonomi. Batasan yang diangkat dari batasan kesehatan menurut Organisasi Kesehatan Dunia (WHO) yang paling baru ini, memang lebih luas dan dinamis dibandingkan dengan batasan sebelumnya yang mengatakan, bahwa kesehatan adalah keadaan sempurna, baik fisik, mental maupun sosial, dan tidak hanya bebas dari penyakit dan cacat (Notoatmodjo, 2007).

Murid Sekolah Dasar merupakan sekelompok masyarakat yang mempunyai besar dalam kelangsungan negara ini sehingga sangat perlu ditingkatkan kemampuan hidup sehat, salah satunya dengan meningkatkan pengetahuan dan sikap murid tentang kesehatan terutama tentang personal hygiene. Kemampuan dan sikap murid dapat ditingkatkan salah satunya dengan memberikan informasi atau penyuluhan kesehatan. Sebagai suatu institusi pendidikan, sekolah mempunyai peranan dan kedudukan strategis dalam upaya promosi kesehatan. Hal ini disebabkan karena sebagian besar anak usia 5-19 tahun berada dalam lembaga pendidikan dalam jangka waktu yang cukup lama. Dari segi populasi, promosi kesehatan di sekolah dapat menjangkau dua jenis populasi, yaitu populasi murid sekolah dan populasi masyarakat umum atau keluarga. Promosi kesehatan di sekolah membantu meningkatkan 
kesehatan murid, guru, karyawan, keluarga serta masyarakat sekitar sehingga proses belajar mengajar berlangsung lebih produktif (Rosso \& Arlianti, 2009).

Hasil survey awal yang peneliti lakukan di Dinas Kesehatan Kota Padang Panjang bahwa masalah personal hygiene dapat dilihat pada tabel dibawah ini :

Tabel 1 Kasus Personal Hygiene di Kota

Padang Panjang Tahun 2017

\begin{tabular}{llc}
\hline NO & \multicolumn{1}{c}{ Nama SD } & $\begin{array}{c}\text { Persentase } \\
(\mathbf{\%})\end{array}$ \\
\hline 1. & $\begin{array}{l}\text { SD Merapi Padang } \\
\text { Panjang }\end{array}$ & $68 \%$ \\
2. & $\begin{array}{l}\text { SD 02 Kampung } \\
\text { Manggis }\end{array}$ & $42 \%$ \\
3. & $\begin{array}{l}\text { SD 07 Silaing } \\
\text { Bawah }\end{array}$ & $36 \%$ \\
4. & SD 15 Tanah & $32 \%$ \\
5. & Hitam 16 Koto Katik & $28 \%$ \\
\hline
\end{tabular}

Sedangkan dari hasil survey awal yang peneliti lakukan di SD Merapi Padang Panjang pada tanggal 22 Desember 2017 didapatkan jumlah murid SD Merapi Padang Panjang dari kelas 1 sampai kelas 6 yaitu laki - laki berjumlah 62 orang dan perempuan berjumlah 18 orang. Dari wawancara yang peneliti lakukan dengan Kepala Sekolah dari Observasi yang peneliti lakukan terhadap murid SD Merapi Padang Panjang didapatkan bahwa murid di SD tersebut mulai dari kuku yang terlihat panjang dan kotor, serta penampilan rambut yang acak-acakan. Dari data diatas peneliti tertarik untuk meneliti "Hubungan Pengetahaun dan Sikap Murid SD Terhadap Personal Hygiene di SD Merapi Padang Panjang".

\section{METODE PENELITIAN}

Metode penelitian yang digunakan dalam penelitian ini adalah deskriptif korelasional dengan mengunakan desain Cross-Sectional yang merupakan rencana penelitian dengan teknik wawancara, wawancara merupakan pertemuan dua orang untuk bertukar informasi dan ide melalui tanya jawab dan teknik pengamatan dan observasi. Dua di antara yang terpenting adalah proses pengamatan dan ingatan (Sugiyono, 2013).

Populasi dalam penelitian ini adalah seluruh murid SD Merapi Padang Panjang yang berjumlah 80 orang murid.

Pada penelitian ini sampel diambil dengan Teknik Total Sampling.

Alat yang digunakan dalam pengumpulan data adalah daftar pertanyaan dalam bentuk kuesioner merupakan lembaran pertanyaan terhadap responden dimana responden diminta memberi jawaban sesuai dengan petunjuk yang ada pada kuesioner. Analisa data menggunakan analisa univariat dan bivariat. Univariat untuk melihat distribusi frekuensi dari masing-masing variabel independen (Pengetahuan dan sikap) dan variabel dependen (Personal hygiene) dengan menggunakan SPSS.

Analisa bivariat menggunakan uji statistik melalui dua variabel yang diduga berhubungan antara variabel independen (Pengetahuan dan sikap) dengan variabel dependen (personal hygiene), yang menggunakan uji statistik Chi-Square. Bila $p \leq 0,05$ maka $\mathrm{Ha}$ diterima artinya ada hubungan yang bermakna antara kedua variabel, bila $p>0,05$ maka Ho diterima artinya tidak ada hubungan 
yang bermakna antara kedua variabel. Analisis data di lakukan dengan komputerisasi menggunakan metode SPSS.

\section{HASIL DAN PEMBAHASAN}

Tabel1 Distribusi Frekuensi Pengetahuan Murid Tehadap Personal Hygiene

\begin{tabular}{cccc}
\hline N & $\begin{array}{c}\text { Pengeta } \\
\text { huan }\end{array}$ & $\begin{array}{c}\text { Jumlah } \\
(f)\end{array}$ & $\begin{array}{c}\text { Persentase } \\
(\%)\end{array}$ \\
\hline 1 & Tinggi & 37 & 46.2 \\
2 & Rendah & 43 & 53.8 \\
\hline & Total & 80 & 100.0 \\
\hline
\end{tabular}

Berdasarkan tabel diatas dapat dilihat bahwa dari 80 murid separoh diantaranya berpengetahuan rendah terhadap personal hygiene yaitu sebanyak 43 murid (53.8\%).

Tabel 2 Distribusi Frekuensi Sikap Murid Terhadap Personal Hygiene

\begin{tabular}{|c|c|c|c|}
\hline $\begin{array}{l}\mathrm{N} \\
\mathrm{O}\end{array}$ & Sikap & $\begin{array}{c}\text { Jumlah } \\
(f)\end{array}$ & $\begin{array}{c}\text { Persentase } \\
(\%)\end{array}$ \\
\hline 1 & Positif & 39 & 48.8 \\
\hline 2 & Negatif & 41 & 51.2 \\
\hline & Total & 80 & 100.0 \\
\hline
\end{tabular}

Berdasarkan tabel diatas dapat dilihat bahwa dari 80 murid separoh diantaranya bersikap negatif terhadap personal hygiene yaitu sebanyak 41 murid (51.2\%).

Tabel 3 Distribusi Frekuensi Personal Hygiene Murid

\begin{tabular}{cccc}
\hline $\mathrm{N}$ & $\begin{array}{c}\text { Personal } \\
\mathrm{o}\end{array}$ & $\begin{array}{c}\text { Humlah } \\
(f)\end{array}$ & $\begin{array}{c}\text { Persentase } \\
(\%)\end{array}$ \\
\hline 1 & Baik & 36 & 45,0 \\
2 & Buruk & 44 & 55,0 \\
\hline & Total & 80 & 100.0 \\
\hline
\end{tabular}

Berdasarkan tabel diatas dapat dilihat bahwa dari 80 murid separoh diantaranya memiliki personal hygiene yang buruk yaitu sebanyak 44 murid $(55 \%)$.
Tabel 4 Hubungan Pengetahuan Dengan Personal Hygiene

\begin{tabular}{lccccc}
\hline \multirow{2}{*}{$\begin{array}{l}\text { Pengeta } \\
\text { huan }\end{array}$} & \multicolumn{3}{c}{ Personal Hygiene } & \\
\cline { 2 - 5 } & \multicolumn{4}{c}{ P- } \\
& \multicolumn{2}{c}{ Baik } & \multicolumn{2}{c}{ Buruk } & Value \\
\cline { 2 - 5 } & $f$ & $\%$ & $f$ & $\%$ & \\
\hline Tinggi & 29 & 78.3 & 8 & 21.6 & \multirow{2}{*}{0,000} \\
Rendah & 7 & 16.3 & 36 & 83.7 & \\
\hline Total & 36 & & 44 & & \\
\hline
\end{tabular}

Dari tabel diatas dapat dilihat dari 43 murid yang berpengetahuan rendah terdapat lebih dari separoh memiiki personal hygiene yang buruk yaitu sebanyak 36 orang $(83.7 \%)$.

Berdasarkan uji statistik chisquere diperoleh nilai $\mathrm{p}=0,000$ $(\mathrm{p} \leq 0,05)$ menunjukkan bahwa $\mathrm{Ha}$ diterima, artinya terdapat hubungan yang signifikan antara tingkat pengetahuan dengan personal hygiene murid SD Merapi Padang Panjang.

Menurut Green (1980) dalam Notoadmodjo (2007), mengemukakan bahwa faktor predisposisi yang mempengaruhi perilaku seseorang adalah pengetahuan yaitu hasil penginderaan manusia terhadap objek diluarnya melalui indera-indera yang dimilikinya. Dengan sendirinya pada waktu penginderaan, dalam diri manusia terjadi proses perhatian, persepsi, penghayatan terhadap stimulus atau objek diluar subjek. Sehingga dapat disimpulkan bahwa pengetahuan dapat di ukur atau di observasi melalui apa yang diketahui tentang objek.

Personal hygiene merupakan suatu kesehatan perorangan dalam memelihara kesehatan diri sendiri, memperbaiki dan mempertinggi nilai kesehatan serta mencegah timbulnya penyakit (Depkes RI, 2001).

Penelitian ini sejalan dengan penelitian (Fatmawati, 2018) dengan 
judul Pengaruh pendidikan Kesehatan Terhadap Pengetahuan Tentang Personal Hygiene Pada Anak Usia Sekolah. Hasil penelitian diperoleh nilai $p$-value $=0,00<0,05$ dengan selisih nilai mean -2.35 . Hal ini menunjukkan ada pengaruh yang signifikan antara pengetahuan responden sebelum dengan setelah diberikan pendidikan kesehatan . disini dapat disimpulkan bahwa pengetahuan responden mengalami perubahan yang signifikan setelah diberikan pendidikan kesehatan.

Menurut penelitian yang dilakukan oleh Tiara (2013), mengatakan murid dengan pengetahuan tinggi tentang kebersihan diri akan memiliki resiko lebih kecil terjadinya personal hygiene yang buruk ditunjukkan dengan hasil dari 76 murid diperoleh 35 orang yang memiliki pengetahuan yang rendah, ditunjukkan dengan nila $\mathrm{p}=0,000(p \leq$ 0,005).

$$
\text { Menurut asumsi peneliti }
$$

Penelitian yang dilakukan di SD Merapi Padang Panjang menemukan bahwa terdapat hubungan antara pengetahuan dan personal hygiene. Murid yang mempunyai pengetahuan yang tinggi tentang personal hygiene akan memiliki resiko lebih kecil terjadinya personal hygiene yang buruk, karena pengetahuan merupakan dasar bagi murid untuk menentukan tindakan dalam pelaksanaan personal hygiene.

Tabel 5 Hubungan Sikap Dengan Personal Hygiene

\begin{tabular}{|c|c|c|c|c|c|}
\hline \multirow{3}{*}{ Sikap } & \multicolumn{4}{|c|}{ Personal Hygiene } & \multirow{3}{*}{$\begin{array}{c}\text { P- } \\
\text { Value }\end{array}$} \\
\hline & & aik & & ruk & \\
\hline & $f$ & $\%$ & $J$ & $\%$ & \\
\hline
\end{tabular}

\begin{tabular}{lrrrrr}
\hline Positif & 29 & 74.4 & 10 & 25.6 & \multirow{2}{*}{0,000} \\
Negatif & 7 & 17.1 & 34 & 82.9 & \\
\cline { 1 - 4 } Total & 36 & & 44 & & \\
\cline { 1 - 4 }
\end{tabular}

Dari tabel diatas dapat dilihat dari 41 murid yang bersikap negatif terdapat lebih dari separoh memiiki personal hygiene yang buruk yaitu sebanyak 34 orang $(82.9 \%)$.

Berdasarkan uji statistik chisquere diperoleh nilai $\mathrm{p}=0,000$ $(p \leq 0,05)$ menunjukkan bahwa $\mathrm{Ha}$ diterima, artinya terdapat hubungan yang signifikan antara sikap murid dengan personal hygiene murid SD Merapi Padang Panjang.

Teori Bloom dalam Notoadmodjo (2007), menyatakan bahwa sikap merupakan presdisposisi yang menentukan bagaimana seseorang akan bertindak, dan juga sikap merupakan reaksi atau respon emosional seseorang terhadap stimulus yang dapat dilanjutkan dengan kecendrungan untuk melakukan atau tidak melakukan tindakan terhadap objek.

Penelitian ini juga didukung oleh Aini (2013), sikap merupakan respon yang masih tertup dari seseorang terhadap suatu stimulus atau objek. Peningkatan pengetahuan ini berdampak pada terbentuknya sikap siswa terhadap kemampuan melakukan pencengahan penularan scabies. Pendidikan kesehatan melalui ceramah yang dingunakan untuk menyampaikan informasi tentang penyakit scabies itu menimbulkan pengetahuan.

Penelitian yang sama dilakukan oleh Wijaya (2011), Personal hygiene atau kebersihan diri adalah suatu usaha kesehatan perorangan untuk dapat memelihara kesehatan diri sendiri, memperbaiki dan mempertinggi nilai- 
nilai kesehatan serta mencegah timbulnya penyakit Personal hygiene meliputi kebersihan badan, tangan,kulit / kuku, gigi dan rambut.

Penelitian yang sama juga dilakukan oleh Tiara (2013), mengatakan bahwa sikap murid yang positif merupakan upaya pencegahan agar tidak tertular penyakit akibat kurang menjaga personal hygiene. Hasil analisa bivariat didapatkan adanya hubungan antara sikap dengan personal hygiene diperoleh dari 76 murid diperoleh 29 murid memiliki sikap negatif dan pesonal hygiene buruk, hal ini ditunjukkan dengan uji statistik chi-squere nilai $\mathrm{p}=0,000(p \leq$ 0,005).

Menurut asumsi peneliti sikap murid di SD Merapi Padang Panjang yang negatif tentang personal hygiene menimbulkan tindakan yang buruk. Sehingga mereka tidak bertindak dan merespon untuk melakukan tindakan personal hygiene yang baik.

Murid yang mempunyai sikap positif terhadap personal hygiene berkemungkinan besar akan memiliki personal hygiene yang baik, begitupun sebaliknya murid yang mempunyai sikap negatif terhadap personal hygiene berkemungkinan besar akan memiliki personal hygiene yang buruk, karena sikap positif menjadikan prilaku yang baik serta murid akan melakukan upaya pencegahan agar tidak tertular penyakit akibat kurang menjaga personal hygiene dan sikap negatif menjadikan prilaku buruk pada murid serta murid tidak berupaya melakukan pencegahan yang menimbulkan penyakit.

Diharapkan kepada murid SD Merapi Padang Panjang agar lebih meningkatan pengetahuan tentang personal hygiene di SD Merapi
Padang Panjang, karena adanya pengetahuan tersebut lebih bisa memanfatkan fasilitas tentang kebersihan dan menjadi prilaku yang bermaanfaat bagi kesehatan kita atau pun lingkungan sekolah.

\section{SIMPULAN}

Berdasarkan hasil penelitian yang telah dilakukan tentang tentang Hubungan Pengetahuan dan Sikap Murid SD Terhadap Personal Hygiene di SD Merapi Padang Panjang maka dapat ditarik kesimpulan sebagai berikut:

1. Pengetahuan murid tentang personal hygiene di Sekolah Dasar Merapi Padang Panjang tergolong pada kategori rendah sebanyak 43 murid $(53,8 \%)$.

2. Sikap murid tentang personal hygiene di Sekolah Dasar Merapi Padang Panjang tergolong negatif sebanyak 41 murid $(51,2 \%)$.

3. Terdapat hubungan yang signifikan antara pengetahuan murid dan sikap dengan personal hygiene di SD Merapi Padang Panjang Tahun 2018 ditunjukkan dengan nilai $p=0,000(\alpha \leq 0,05)$.

\section{SARAN}

Diharapkan bagi institusi pendidikan agar dapat menerapkan langsung mata kuliah promosi kesehatan dengan melakukan penyuluhan tentang personal hygiene ke sekolah dasar, sehingga mampu meningkatkan pengetahuan dan sikap murid dalam personal hygiene.

Selain itu diharapkan kepada guru lebih memperhatikan pengetahuan dan 
sikap terhadap personal hygiene murid SD karena pengetahuan dan sikap dapat memberikan pengaruh paling besar terhadap status kesehatan

\section{DAFTAR PUSTAKA}

1. Ali, M.dkk. (2006). Ilmu dan Aplikasi Pendidikan. Edisi Pertama. Bandung : Pedagogiana Press

2. Andarmoyo Sulistyo. (2012).. Personal hygiene Konsep, Proses

3. Azwar, S. (2012). Sikap dan Perilaku. Dalam : Sikap Manusia Teori dan Pengukurannya. Yogyakarta: Pustaka Pelajar, 3-22 dan Aplikasi dalam Praktik keperawatan. Yogyakarta : Graha ilmu

4. Isro'in, Laily., Andarmoyo, Sulistyo. (2012). Personal Hygiene Konsep, Proses dan Aplikasi dalam Praktek Keperawatan.

5. Kemkes RI. (2011). Higiene dan Sanitasi Pangan. http://gizi.depkes.go.id/wpcontent/uploads/2015/02/higien e-sanitasi-pangan-dit-gizi1. pdf. Diakses 2011

6. Notoatmodjo, S. (2007). Promosi Kesehatan \& Ilmu Perilaku. Jakarta: RINEKA CIPTA

7. (2010). Metodologi Penelitian
Kesehatan. Jakarta : Rineka Cipta.

8. Pratiwi \& Noviar. (2008) "Hubungan Pengetahuan dan Sikap Siswa terhadap PHBS di SDN Ngebel Kec. Kasihan Kabupaten Bantul, Yogyakarta.

9. Pratiwi \& Noviar. (2008) "Hubungan Pengetahuan dan Sikap Siswa terhadap PHBS di SDN Ngebel Kec. Kasihan Kabupaten Bantul : Yogyakarta.

10. Saifuddin, Anwar. (2012). Sikap Manusia (Teori danPengukurannya).

Yogyakarta: PT. Pustaka Pelajar.

11. Poltekkes Palembang. (2012) hubungan pengetahuan dan sikap dengan perilaku.pdf

12. Siwach, Meena. (2009). Impact of Health Education Programme on the Knowledge and Practices of School Children Regarding Personal Hygiene in Rural Panipat : Kamla-Raj Int J Edu Sci, 1(2): 115-118

13. Sugiyono. (2012). Metode Penelitian Kuantitatif Kualitatif dan R\&D. Bandung : Alfabeta.

14. Tarwoto \& Wartonah. (2006). Kebutuhan Dasar Manusia Dan Proses Keperawatan. Edisi Ke-3. Jakarta : Salemba Medika. 
15. Kusumawati, dkk. (2008). Hubungan antara Pendidikan dan Pengetahuan Kepala Keluarga Tentang Kesehatan Lingkungan dengan Perilaku Hidup Bersih dan Sehat (PHBS).

http://www.typecat.com/pdf/jur nal pengetahuan-masyarakattentang-phbs.html.

DiaksesTanggal23 Juni2011

16. (Fatmawati, 2018) Pengaruh Pendidikan Kesehatan TerhadapPengetahuan

Tentang Personal Hygiene Pada Anak Usia Sekolah Di Sdn 206/Iv Kota Jambi http://jab.stikba.ac.id/index.ph p/jab/article/view/56/48

17. Wong. (2009). Buku Ajar Keperawatan Pediatrik Volume 1. Jakarta : EGC. 